\title{
Association of Comorbidities with Survival in Elderly Patients with Metastatic Bladder Cancer Treated with Chemotherapy
}

Ki Hyang Kim ( $\sim$ pori76@hanmail.net)

Inje University Busan Paik Hospital

\section{Research Article}

Keywords: Bladder cancer, Comorbidity, Prognosis

Posted Date: June 7th, 2021

DOl: https://doi.org/10.21203/rs.3.rs-579210/v1

License: (c) (i) This work is licensed under a Creative Commons Attribution 4.0 International License.

Read Full License 


\section{Abstract}

\section{Introduction}

Bladder cancer has a high incidence in elderly patients who have complex comorbidities. There are no data on the association between the comorbidities and overall survival (OS) of elderly patients with metastatic bladder cancer treated with chemotherapy; therefore, we evaluated the comorbidities of these patients.

\section{Methods}

We retrospectively reviewed the data of stage IV bladder cancer patients $>65$ years of age who underwent chemotherapy at the Busan Paik Hospital between 2008 and 2018. The comorbidities were assessed using the Cumulative Illness Rating Scale-Geriatric.

\section{Results}

We retrospectively reviewed the data of 22 patients. The median age at diagnosis was 71.5 years. The most common comorbidities were genitourinary and hematopoietic diseases. The median OS of all patients was 23.9 months (95\% confidence interval: 4.9-42.8). Based on the univariate and multivariate analyses of the prognostic factors associated with OS, no comorbidity categories were found to be associated with OS.

\section{Conclusions}

Although this was a small, retrospective, single-center study, no comorbidity categories were associated with OS. We should not hesitate to treat elderly patients with metastatic bladder cancer, and we should always evaluate their comorbidities in clinical practice.

\section{Introduction}

Bladder cancer is the ninth most common cancer worldwide and the 10th most common cancer in South Korea $[1,2]$. Its incidence rates increase in patients older than 65 years of age, and the highest rates are found in patients aged $75-84$ years

Elderly patients have complex comorbidities, functional impairments or mobility disabilities, and geriatric syndrome. The comorbidities of elderly patients with cancer influence the treatment, survival, cancer risk, and recurrence [3-6]. The evaluation of the comorbidities of elderly patients with cancer is important to determine the process of management. Although most patients with bladder cancer treated with chemotherapy are elderly people, there are no data regarding the association between their comorbidities and survival. Therefore, this study aimed to evaluate the comorbidities of elderly patients with bladder cancer treated with chemotherapy and to analyze the comorbidities associated with survival. 


\section{Materials And Methods}

We retrospectively reviewed the data of stage IV bladder cancer patients $>65$ years of age who underwent chemotherapy at the Busan Paik Hospital between 2008 and 2018. The comorbidities were assessed using the Cumulative Illness Rating Scale-Geriatric (CIRS-G), which includes 14 organ categories and grades each comorbidity according to severity (score of $0-4)[7,8]$. The following clinical data were obtained: demographics (age and sex), Eastern Cooperative Oncology Group performance status (ECOG PS), site of metastasis, previous treatment, MAX2 index, and adverse events (AEs). The MAX2 index describes the overall risk of the severe toxicity of a regimen with the highest frequency of both grade 4 hematologic toxicity and grade 3-4 non-hematologic toxicity and shows the correlation with the overall risk of severe toxicity by ECOG trials. AEs were graded according to the National Cancer Institute Common Terminology Criteria for AEs ver. $4.0[9,10]$. All data were collected from the electronic medical records of the Busan Paik Hospital. We analyzed the associations of the comorbidities, overall survival (OS), and AEs using the Cox proportional hazard regression model. All data analyses were conducted using SPSS version 25. All p-values were two-sided, and a p-value $<0.05$ was deemed statistically significant. This study was approved by the Institutional Review Board of the Busan Paik Hospital (IRB No.20-0164).

\section{Results}

\section{Patient characteristics}

The data of 22 patients were evaluated. The patients' characteristics are listed in Table 1. The median age at diagnosis was 71.5 years. Most patients (81.8\%) were male, and $81.9 \%$ had an ECOG PS of 0 or 1. Most of the sites of metastasis (54.6\%) were the lymph nodes. Ten (45.5\%) patients had previous surgery. The median MAX2 index score of chemotherapy was 0.285 . The median number of chemotherapy cycles administered was 4. 
Table 1

Patients' characteristics

\begin{tabular}{|ll|}
\hline Characteristics & All patients $(\mathrm{N}=22)$ \\
\hline Age at diagnosis, median (range) & 71.5 years $(65-84)$ \\
\hline Gender, $\mathrm{n}(\%)$ & $18(81.8)$ \\
\hline Male & $4(18.2)$ \\
\hline Female & \\
\hline ECOG Performance status, $\mathrm{n}(\%)$ & $3(13.7)$ \\
\hline 0 & $15(68.2)$ \\
\hline 1 & $3(13.6)$ \\
\hline 2 & $1(4.5)$ \\
\hline Site of metastasis, $\mathrm{n}(\%)$ & $12(54.6)$ \\
\hline Lymph node only & $3(13.6)$ \\
\hline Lung only & $2(9.1)$ \\
\hline Bone only & $5(22.7)$ \\
\hline others & $10(45.5)$ \\
\hline Previous treatment, $\mathrm{n}(\%)$ & 0.285 \\
\hline Operation & $4(4-6)$ \\
\hline Median MAX 2 score & \\
\hline Median number of chemotherapy cycle & \\
\hline
\end{tabular}

\section{Comorbidities}

The comorbidity distribution for all patients according to the CIRS-G scores is shown in Fig. 1. The most common comorbidities were genitourinary and hematopoietic diseases. The categories for a CIRS-G score of 3 were hematopoietic and upper gastrointestinal (GI) diseases. There were no categories for a CIRS-G score of 4. The distribution of the total CIRS-G score is shown in Fig. 2. All patients had at least one comorbidity. The median total CIRS-G score was 5 (1-20). Five patients had a CIRS-G score of 3 and a median severity index of $1.67(1.0-2.5)$.

\section{AEs associated with chemotherapy}


The treatment-related AEs are summarized in Table 2. All-grade hematologic AEs occurred in 19 patients, five of whom had a CIRS-G score of 3 . The most common hematologic AE was anemia $(N=9,40.9 \%)$. Three patients had grade 4 neutropenia, and one patient had grade 4 febrile neutropenia.

Table 2

Adverse events in all patients

\begin{tabular}{|ll|}
\hline Adverse events & $\mathrm{N}(\%)$ \\
\hline Hematologic toxicity of all grades, $\mathrm{n}(\%)$ & $19(86.4)$ \\
\hline Grade 1 hematologic toxicity & $6(27.3)$ \\
\hline Anemia, $\mathrm{n}(\%)$ & $4(18.2)$ \\
\hline Thrombocytopenia, $\mathrm{n}(\%)$ & \\
\hline Grade 2 hematologic toxicity & $9(40.9)$ \\
\hline Anemia, $\mathrm{n}(\%)$ & $1(4.5)$ \\
\hline Neutropenia, $\mathrm{n}(\%)$ & $3(13.6)$ \\
\hline Thrombocytopenia, $\mathrm{n}(\%)$ & \\
\hline Grade 3 hematologic toxicity & $2(9.1)$ \\
\hline Anemia, $\mathrm{n}(\%)$ & $2(9.1)$ \\
\hline Neutropenia, $\mathrm{n}(\%)$ & $1(4.5)$ \\
\hline Thrombocytopenia, $\mathrm{n}(\%)$ & \\
\hline Grade 4 hematologic toxicity & $3(13.6)$ \\
\hline Neutropenia, $\mathrm{n}(\%)$ & $1(4.5)$ \\
\hline Febrile neutropenia, $\mathrm{n}(\%)$ & $2(9.1)$ \\
\hline Non-hematologic toxicity of all grades, $\mathrm{n}(\%)$ & \\
\hline
\end{tabular}

OS

The median OS of all patients was 23.9 months (95\% confidence interval: 4.9-42.8) (Fig. 3). Based on the univariate and multivariate analyses of prognostic factors, no categories were found to be associated with OS (Table 3). 
Table 3

Univariate Cox regression analysis for OS

\begin{tabular}{|c|c|c|c|}
\hline Variables & Level & $\mathrm{HR}(95 \% \mathrm{Cl})$ & $p$ \\
\hline Gender (ref = Male) & Female & $1.94(0.62-6.12)$ & 0.257 \\
\hline PS ECOG (ref = 0-1) & $\geq 2$ & $1.92(0.92-3.99)$ & 0.081 \\
\hline Age at Diagnosis & & $0.99(0.89-1.10)$ & 0.907 \\
\hline Number of CIRS-G score $3($ ref $=0)$ & $>=1$ & $1.82(0.57-5.75)$ & 0.310 \\
\hline Heart $($ ref $=0)$ & $1-4$ & $4.7(0.53-42.79)$ & 0.162 \\
\hline Vascular $($ ref $=0)$ & $1-4$ & $0.68(0.25-1.79)$ & 0.431 \\
\hline Hematopoietic (ref = 0) & $1-4$ & $2.66(0.75-9.37)$ & 0.128 \\
\hline Respiratory $(r e f=0)$ & $1-4$ & $1.85(0.51-6.65)$ & 0.346 \\
\hline Upper GI (ref = 0) & $1-4$ & $0.04(0-94.81)$ & 0.420 \\
\hline Liver $($ ref $=0$ ) & $1-4$ & $0.52(0.07-3.99)$ & 0.528 \\
\hline Renal $($ ref $=0$ ) & $1-4$ & $0.49(0.07-3.76)$ & 0.496 \\
\hline Endocrine $($ ref $=0)$ & $1-4$ & $1.17(0.24-5.47)$ & 0838 \\
\hline Anemia $(r e f=0)$ & $1-4$ & $1.81(0.51-6.40)$ & 0.355 \\
\hline Neutropenia $(r e f=0)$ & $1-4$ & $0.46(0.15-1.42)$ & 0.175 \\
\hline Thrombocytopenia $($ ref $=0$ ) & $1-4$ & $0.71(.025-1.98)$ & 0.513 \\
\hline
\end{tabular}

\section{Discussion}

This is the first retrospective study conducted to evaluate the association between the comorbidities and survival of elderly patients with metastatic bladder cancer treated with chemotherapy in South Korea. The median OS of all patients was 23.9 months. No categories of comorbidities or clinical factors were associated with OS. Many studies have shown that comorbidities are associated with survival and cancer treatment [11-14]. In a previous study, the comorbidities were evaluated using the Charlson Comorbidity Index (CCl), which showed that cancer survival and treatment are associated with the $\mathrm{CCl}$ grade. However, in this study, the comorbidities were evaluated using CIRS-G, which showed the associations of each category with the survival of patients who underwent chemotherapy. Although no comorbidity categories were associated with survival, two studies showed that each category is associated with the survival of elderly patients with cancer $[15,16]$. The most common comorbidities were genitourinary and hematopoietic diseases. The categories of a CIRS-G score of 3 were hematopoietic and upper GI diseases, while there were no categories for a CIRS-G score of 4 . 
All patients underwent gemcitabine and platinum chemotherapy. Therefore, the median MAX2 score was 0.285. The most common AEs of chemotherapy were grade 1-2 hematologic toxicities, which most commonly includes anemia and thrombocytopenia. One patient had a grade 4 febrile neutropenia. All patients tolerated gemcitabine combined with platinum chemotherapy.

This study had several limitations. It was a small, retrospective, single-institution study. The median OS of 23.9 months was longer than that in the current population. Selection bias was a possible cause associated with survival. The small population limited the evaluations of the association of comorbidities with survival and toxicities. In addition, we did not routinely evaluate the comorbidities in our hospital, as the electronic medical records were insufficient to provide these data. However, this study is the first to show the association between the comorbidities and survival of elderly patients with metastatic bladder cancer treated with chemotherapy, showing that no comorbidity categories were associated with survival. Thus, we should not hesitate to treat elderly patients with metastatic bladder cancer, and we should always evaluate their comorbidities in clinical practice.

\section{Declarations}

\section{Data availability}

Data are available upon request.

\section{Acknowledgement}

None.

\section{Statement of Ethics}

This study was approved by the Institutional Review Board of the Busan Paik Hospital (IRB No.20-0164). All study procedures were conducted according to the principles of World Medical Association Declaration of Helsinki. Informed consent was waived due to its retrospective study.

\section{Conflict of Interest Statement}

The authors have no conflicts of interest to declare.

\section{Funding Sources:}

This research did not receive any specific grant from funding agencies in the public, commercial, or notfor-profit sectors. 


\section{Author Contributions}

The author confirms sole responsibility for the following: study conception and design, data collection, analysis and interpretation of results, and manuscript preparation.

\section{References}

1. Antoni S, Ferlay J, Soerjomataram I, Znaor A, Jemal A, Bray F. Bladder cancer incidence and mortality: a global overview and recent trends. Eur Urol. 2017;71(1):96-108.

2. Jung KW, Won YJ, Kong HJ, Lee ES. Cancer statistics in Korea: incidence, mortality, survival, and prevalence in 2016. Cancer Res Treat. 2019;51(2):417-30.

3. Søgaard M, Thomsen RW, Bossen KS, Sørensen HT, Nørgaard M. The impact of comorbidity on cancer survival: a review. Clin Epidemiol. 2013;5(Suppl 1):3-29.

4. Lee L, Cheung WY, Atkinson E, Krzyzanowska MK. Impact of comorbidity on chemotherapy use and outcomes in solid tumors: a systematic review. J Clin Oncol. 2011;29(1):106-17.

5. Williams GR, Mackenzie A, Magnuson A, Olin R, Chapman A, Mohile S, et al. Comorbidity in older adults with cancer. J Geriatr Oncol. 2016;7(4):249-57.

6. Extermann M. Interaction between comorbidity and cancer. Cancer Control. 2007;14(1):13-22.

7. Miller MD, Paradis CF, Houck PR, Mazumdar S, Stack JA, Rifai AH, et al. Rating chronic medical illness burden in geropsychiatric practice and research: application of the Cumulative Illness Rating Scale. Psychiatry Res. 1992;41(3):237-48.

8. Extermann M. Measuring comorbidity in older cancer patients. Eur J Cancer. 2000;36(4):453-71.

9. Extermann M, Chen H, Cantor AB, Corcoran MB, Meyer J, Grendys E, et al. Predictors of tolerance to chemotherapy in older cancer patients: a prospective pilot study. Eur J Cancer. 2002;38(11):146673.

10. Extermann M, Meyer J, McGinnis M, Crocker TT, Corcoran MB, Yoder J, et al. A comprehensive geriatric intervention detects multiple problems in older breast cancer patients. Crit Rev Oncol Hematol. 2004;49(1):69-75.

11. Boakye D, Rillmann B, Walter V, Jansen L, Hoffmeister M, Brenner H. Impact of comorbidity and frailty on prognosis in colorectal cancer patients: A systematic review and meta-analysis. Cancer Treat Rev. 2018;64:30-9.

12. Gurney J, Sarfati D, Stanley J. The impact of patient comorbidity on cancer stage at diagnosis. $\mathrm{Br} \mathrm{J}$ Cancer. 2015;113(9):1375-80.

13. Huang Y, Chen W, Haque W, Verma V, Xing Y, Teh BS, et al. The impact of comorbidity on overall survival in elderly nasopharyngeal carcinoma patients: a National Cancer Data Base analysis. Cancer Med. 2018;7(4):1093-101.

14. Morishima T, Matsumoto Y, Koeda N, Shimada H, Maruhama T, Matsuki D, et al. Impact of comorbidities on survival in gastric, colorectal, and lung cancer patients. J Epidemiol. 
2019;29(3):110-5.

15. Kim KH, Lee JJ, Kim J, Zhou JM, Gomes F, Sehovic M, et al. Association of multidimensional comorbidities with survival, toxicity, and unplanned hospitalizations in older adults with metastatic colorectal cancer treated with chemotherapy. J Geriatr Oncol. 2019;10(5):733-41.

16. Lee JJ, Kim J, Sehovic M, Chen L, Extermann M. Using heat maps to assess the multidimensional association of comorbidities with survival in older cancer patients treated with chemotherapy. $J$ Geriatr Oncol. 2017;8(5):336-42.

Figures

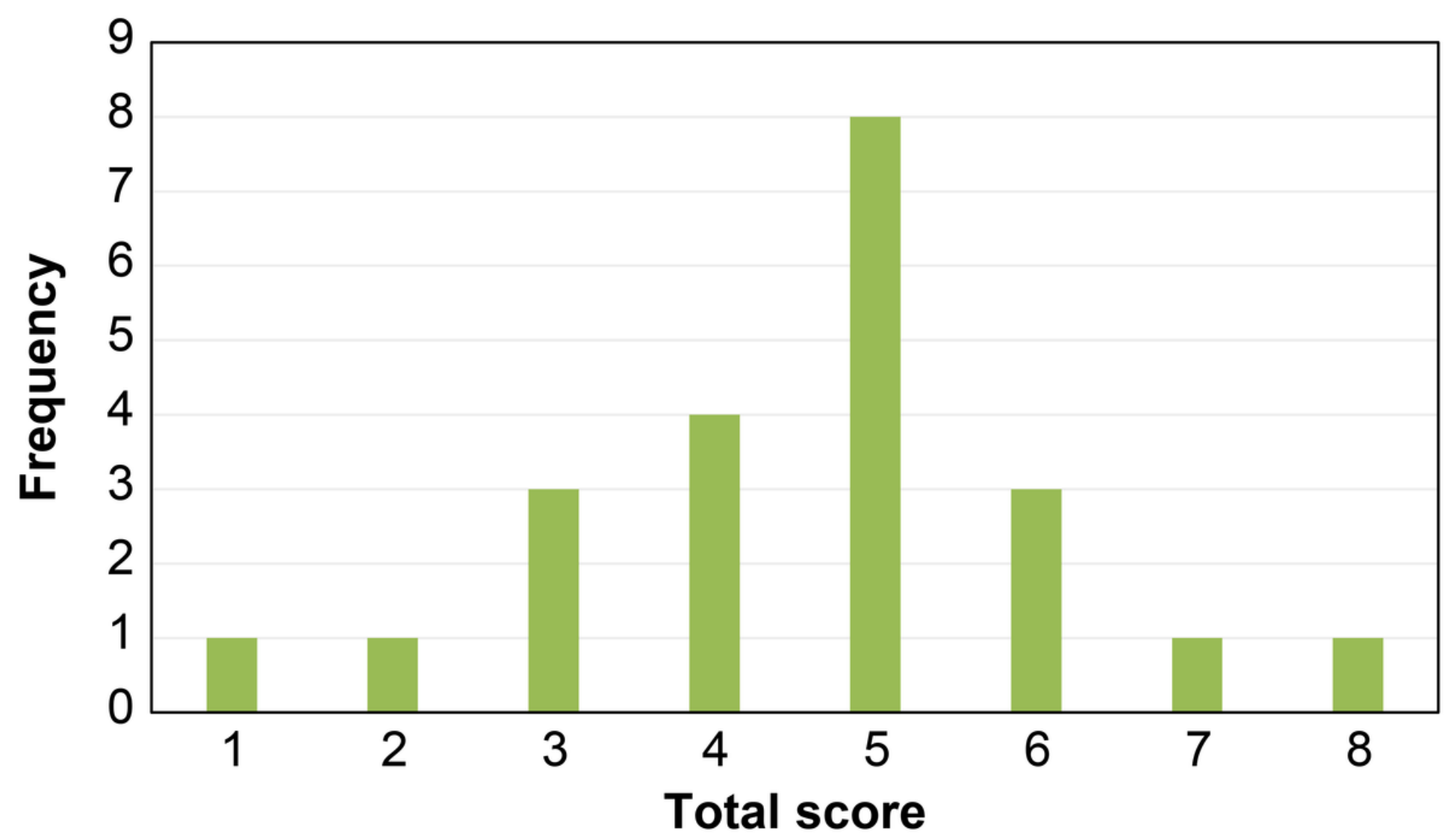

Figure 1

Comorbidity distribution according to the CIRS-G grade. 
CIRS-G

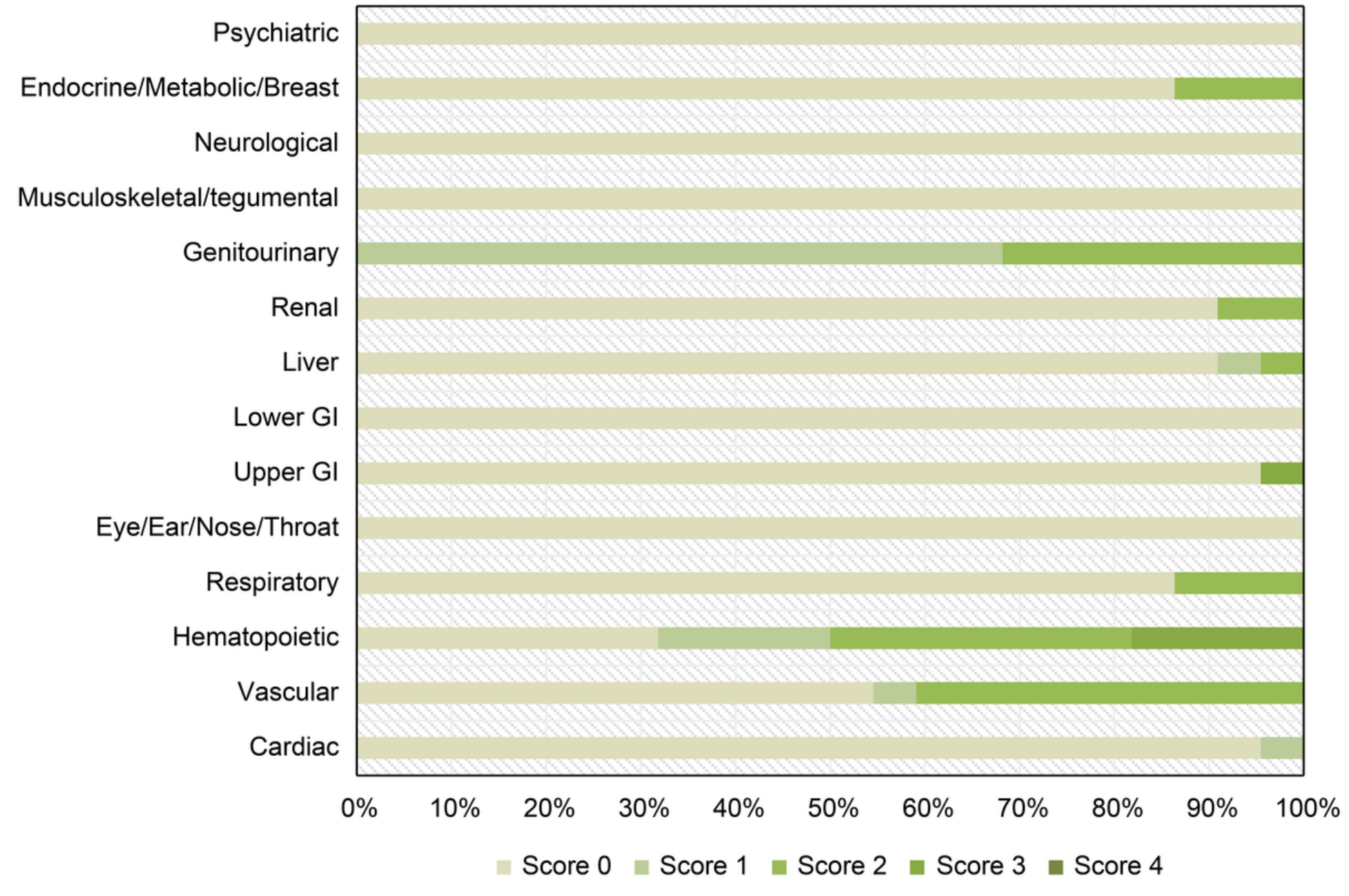

Figure 2

Distribution of the total CIRS-G score. 


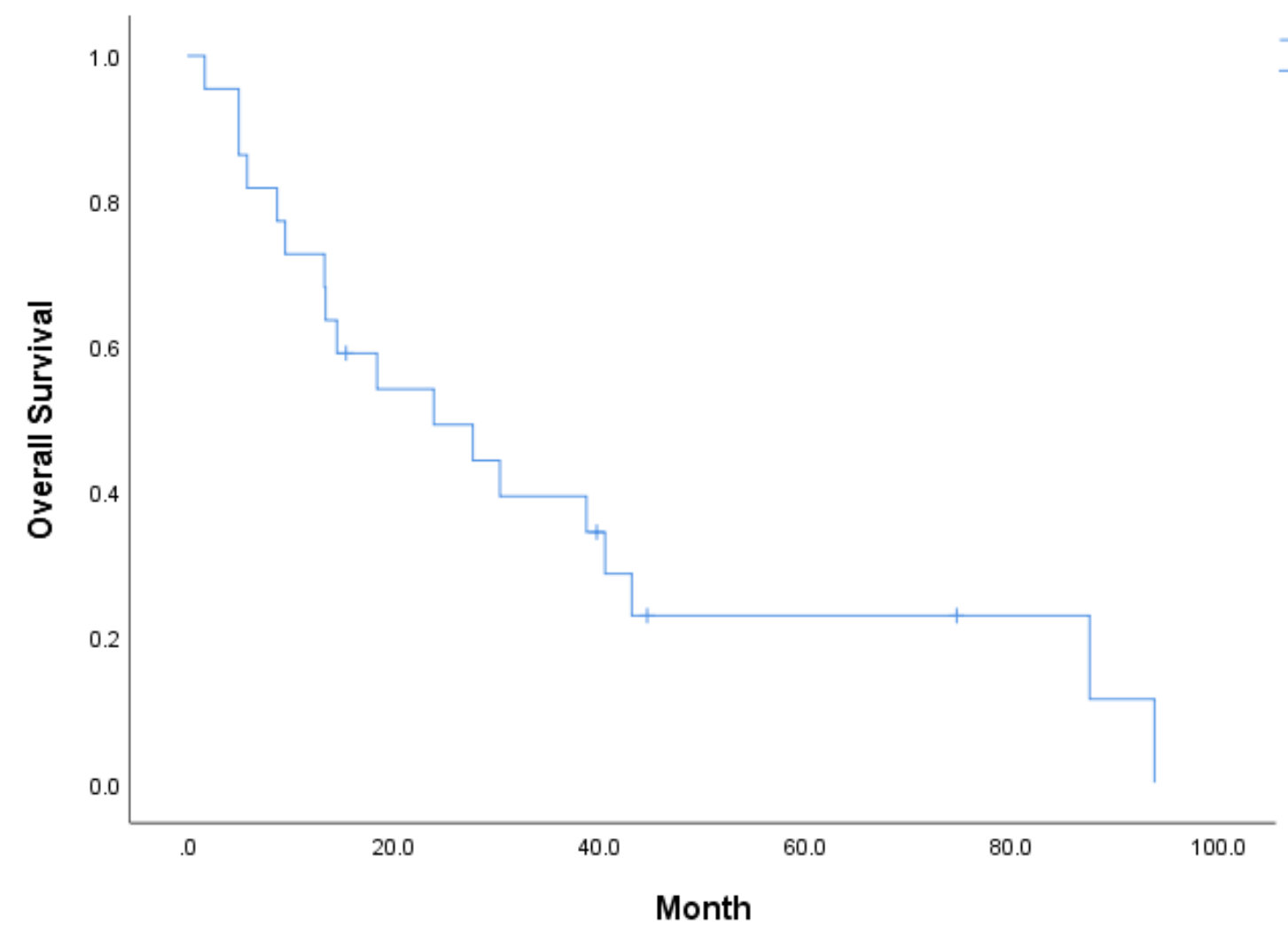

\section{Figure 3}

Kaplan-Meier estimates of the overall survival. 